Annals of International Medical and Dental Research

E-ISSN: 2395-2822 | P-ISSN: 2395-2814

Vol-8, Issue-2 | March-April 2022

DOI: $10.53339 /$ aimdr.2022.8.2.18

Page no- 128-134 | Section- Research Article (Surgery)

\title{
Tube Thoracostomy Surgery among COVID-19 Positive Patients in a Tertiary Care Hospital in Bangladesh
}

\author{
Heemel Saha1*, Mohammad Ata Ullah², Redoy Ranjan³, Rakibul Hasan ${ }^{4}$, Asit Baran Adhikary ${ }^{5}$, \\ Debjany Sikder6
}

$\begin{array}{lrrr}{ }^{1} \text { Assistant } & \text { Professor, } & \text { Thoracic } & \text { Surgery } \\ \text { Bangabandhu } & \text { Sheikh } & \text { Mujib } & \text { Medical }\end{array}$ University(BSMMU), Dhaka, Bangladesh.

Email ID: heemelsaha@gmail.com

Orcid ID: 0000-0002-8685-5637

2Assistant Professor, Department of Paediatric Cardiac Surgery, Bangabandhu Sheikh Mujib Medical University(BSMMU), Dhaka, Bangladesh.

Email ID: atau998@gmail.com

Orcid ID: 0000-0002-8685-5637

${ }^{3}$ Assistant Professor, Department of Cardiac Surgery, Bangabandhu Sheikh Mujib Medical University(BSMMU), Dhaka, Bangladesh.

Email ID: redoy_ranjan@yahoo.com

Orcid ID: 0000-0002-8685-5637

4Assistant Professor, Department of Vascular Surgery, Bangabandhu Sheikh Mujib Medical University(BSMMU), Dhaka, Bangladesh.

Email ID: Optioapu28@gmail.com

Orcid ID: 0000-0003-0307-5932,

5Professor, Department of Cardiac Surgery, Bangabandhu Sheikh Mujib Medical University(BSMMU), Dhaka, Bangladesh.

Email ID: drasit2005@yahoo.com

Orcid ID: 0000-0002-8685-5637,

6Dental Surgeon, Al Helal Specialized Hospital, Dhaka, Bangladesh.

Email ID: dejany.sikder@gmail.com

Orcid ID: 0000-0002-6619-9791,

*Corresponding author

Received: 10 December 2021

Revised: 24 January 2022

Accepted: 04 February 2022

Published: 18 February 2022

Keywords:- Tube Thoracostomy Surgery, COVID-19, Pneumothorax, Acute respiratory syndrome.

\section{INTRODUCTION}

A tube thoracostomy for a traumatic hemothorax or pneumothorax is a commonly performed possibly aerosol-generating surgery by acute care surgeons. There is no data on the aerosolization of the severe acute respiratory 
Annals of International Medical and Dental Research

E-ISSN: 2395-2822 | P-ISSN: 2395-2814

Vol-8, Issue-2 | March-April 2022

DOI: 10.53339/aimdr.2022.8.2.18

Page no- 128-134 | Section- Research Article (Surgery)

syndrome coronavirus 2 through tube thoracostomy implantation, and the risk is expected to vary depending on the indication for insertion. This document outlines special precautions to take during the COVID-19 pandemic in order to reduce the risk of infection to workers during tube insertion, drainage system management, and tube removal.[1] The material presented here is not meant to take the place of professional judgment. The lack of any of the special equipment listed below should not preclude or postpone the implantation of a tube thoracostomy in a life-threatening condition, based on the limited data. Some or all of the data and recommendations may not be appropriate to future conditions as the pandemic progresses. The rate of complications after tube thoracostomy placement can be as high as $40 \%$.[2] Tube thoracostomy is commonly performed by several specialties in many hospitals, including surgery, pulmonary, radiology, and emergency medicine, and the risk of complication is directly connected to the proceduralist's skill level and speciality.[3] As a precaution during the COVID-19 epidemic, it is imperative to ensure the safety of all employees. Patients with known or suspected COVID-19 should have their tube thoracostomy placed by the most skilled practitioner and with as few staff members as possible. At the very least, there should be an attending surgeon and a senior resident or fellow on the thoracic procedure team. It is more likely that successful tube placement will be achieved if a thoracic procedure team is on hand to respond to all requests for tube thoracostomy in COVIDpositive patients who are at risk or have been confirmed to be positive. If a formal thoracic procedure team cannot be formed due to logistical issues, then limiting the number of clinicians and specialists performing tube thoracostomy should be seriously considered. [4]

This study's goal is to find and diagnose COVID-19-positive patients who had thoracostomies during the COVID-19 pandemic.

\section{MATERIAL AND METHODS}

In Bangladesh, researchers from a tertiary care hospital's thoracic surgery section did a retrospective analysis. In total, we had 34 participants. All COVID-19 cases requiring thoracic surgery consultation and management that were admitted to the ICU between July 2020 and January 2022 were included in this study. Iatrogenic pneumothorax and other critical cases not associated with COVID-19 were also eliminated.

\section{Data Collection and Analysis}

Charts were assessed for demographic data, comorbidities and patterns of thoracic problems, care and length of stay; intubation and reintubation; ventilatory settings; intervention; outcome; and recovery. In cases of $\mathrm{ME}$ and SE, the clinical approach for SE and ME was followed, which included rigorous clinical and radiological follow-up [3]. Patients who had a pneumothorax due to a daily chest X-ray or a chest $X$-ray taken anytime there was a clinical suspicion of a pneumothorax were given a thoracostomy tube insertion. The data was entered into an excel spreadsheet. SPSS, Version 23, was used to analyze the data.

\section{RESULTS}

There were 34 COVID-19 patients admitted to the ICU, and 22(64.70\%) were male and 
Annals of International Medical and Dental Research E-ISSN: 2395-2822 | P-ISSN: 2395-2814

Vol-8, Issue-2 | March-April 2022

DOI: 10.53339/aimdr.2022.8.2.18

Page no- 128-134 | Section- Research Article (Surgery)

$12(35.3 \%)$ were female. Our study covers a wide range of ages, from 36 to 77.

[Table 1] Showed the distribution of the patient's occupation. Where the highest the highest no of the patient's $(32.4 \%)$ occupation were job followed by $(29.4 \%)$ were house hold worker. The following table shows the details.

Pneumothorax is the most common reason for a tube thoracostomy, accounting for $10(29.4 \%)$ of all instances; traumatic hemothorax accounts for $3(8.8 \%)$ of all cases; hydropneumothorax accounts for $2(5.9 \%)$ of all cases; and massive pleural effusion accounts for $19(55.9 \%)$ of all cases [Table 2].

There were no routine instances and no pleural biopsies or pleurodesis performed. Comorbidities were found in all individuals. There were fourteen cases (41.2\%) of COPD, eight cases $(23.5 \%)$ of Diabetes Mellitus, six cases $(17.6 \%)$ of Chronic Kidney Disease (CKD), and two case $(5.9 \%)$ of a history of CABG [Table 3].

Lung involvement (fibrosis) detected by chest CT scan in twelve patients $40 \%-60 \%$, in fifteen patients $61 \%-80 \%$ and in seven patients $81 \%$ 90\% [Figure 2].

During tube thoracostomy, the patient's condition was 15 cases on a face mask with 10 $\mathrm{lit} / \mathrm{m} \mathrm{O} 2,9$ cases on a non-rebreather mask with 16 lit/m O2, 6 instances on a high flow nasal cannula with 35-60 lit/m O2, and 4 cases on artificial ventilation. The patient's worse condition during tube thoracostomy in 15 cases Face mask with $10 \mathrm{lit} / \mathrm{m} \mathrm{O} 2$ accounted for $44.1 \%$ of the condition [Table 4].

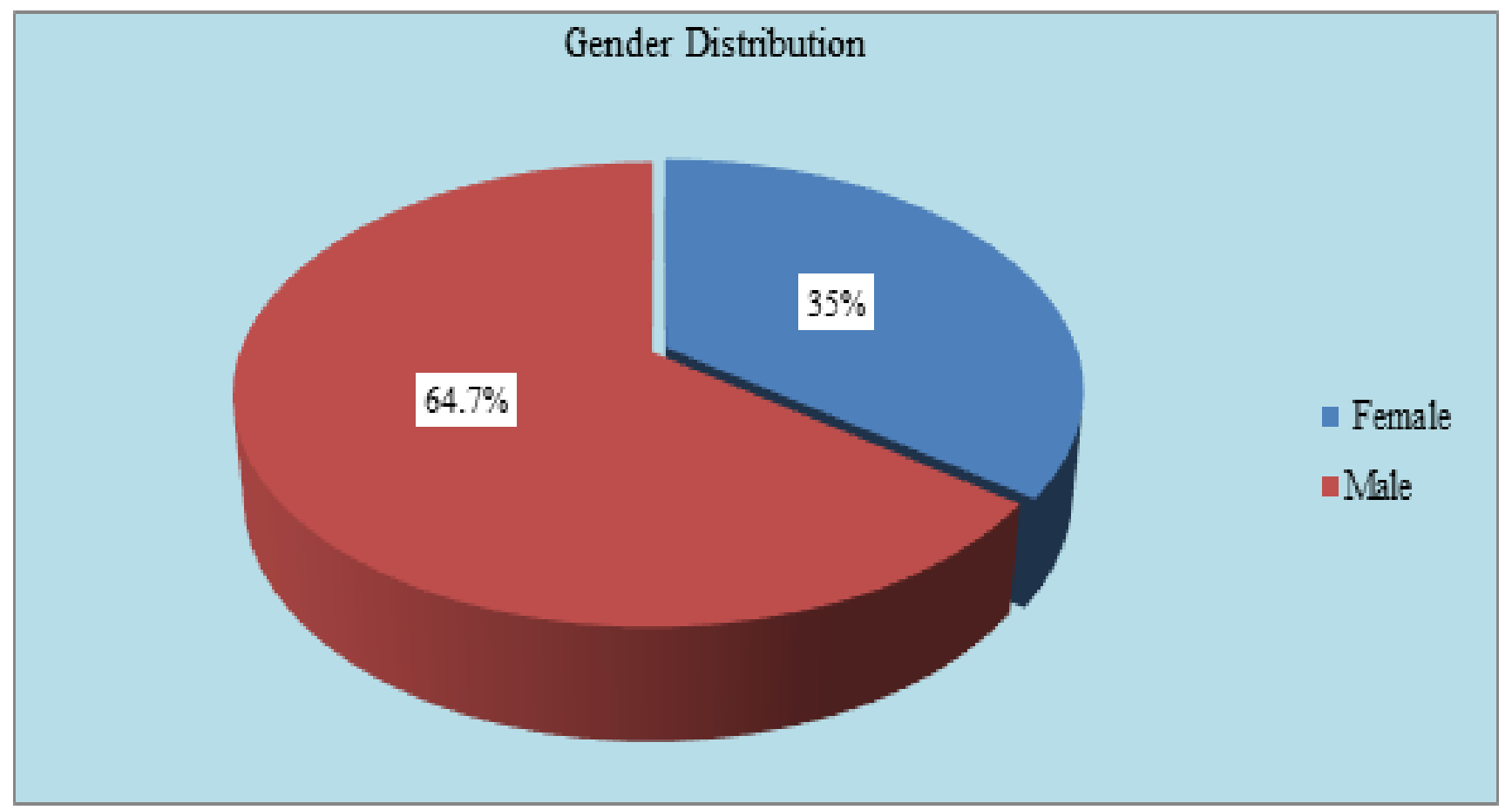

Figure 1: Gender Distribution of the Patients 
Annals of International Medical and Dental Research

E-ISSN: 2395-2822 | P-ISSN: 2395-2814

Vol-8, Issue-2 | March-April 2022

DOI: 10.53339/aimdr.2022.8.2.18

Page no- 128-134 | Section- Research Article (Surgery)

Table 1: Distribution of patient's occupation $(\mathrm{N}=34)$

\begin{tabular}{|c|c|c|}
\hline Occupation & $\mathbf{n}$ & $\%$ \\
\hline Farmer & 5 & $14.7 \%$ \\
\hline Job & 11 & $32.4 \%$ \\
\hline Business & 8 & $23.5 \%$ \\
\hline House hold worker & 10 & $29.4 \%$ \\
\hline
\end{tabular}

Table 2: Cause of Tube Thoracostomy $(\mathrm{N}=34)$

\begin{tabular}{|l|c|c|}
\hline Cause & $\mathbf{n}$ & $\mathbf{\%}$ \\
\hline Pneumothorax & 10 & $29.4 \%$ \\
\hline Traumatic Hemothorax & 3 & $8.8 \%$ \\
\hline Hydropneumothorax & 2 & $5.9 \%$ \\
\hline Massive Pleural Effusion & 19 & $55.9 \%$ \\
\hline
\end{tabular}

Table 3: Distribution of Patients co-morbidities $(\mathrm{N}=34)$

\begin{tabular}{|c|c|c|}
\hline Co-morbidities & $\mathbf{n}$ & $\%$ \\
\hline COPD & 14 & $41.2 \%$ \\
\hline $\mathrm{DM}$ & 8 & $23.5 \%$ \\
\hline Chronic Kidney Disease (CKD) & 6 & $17.6 \%$ \\
\hline DM with IHD & 4 & $11.8 \%$ \\
\hline History of CABG & 2 & $5.9 \%$ \\
\hline
\end{tabular}

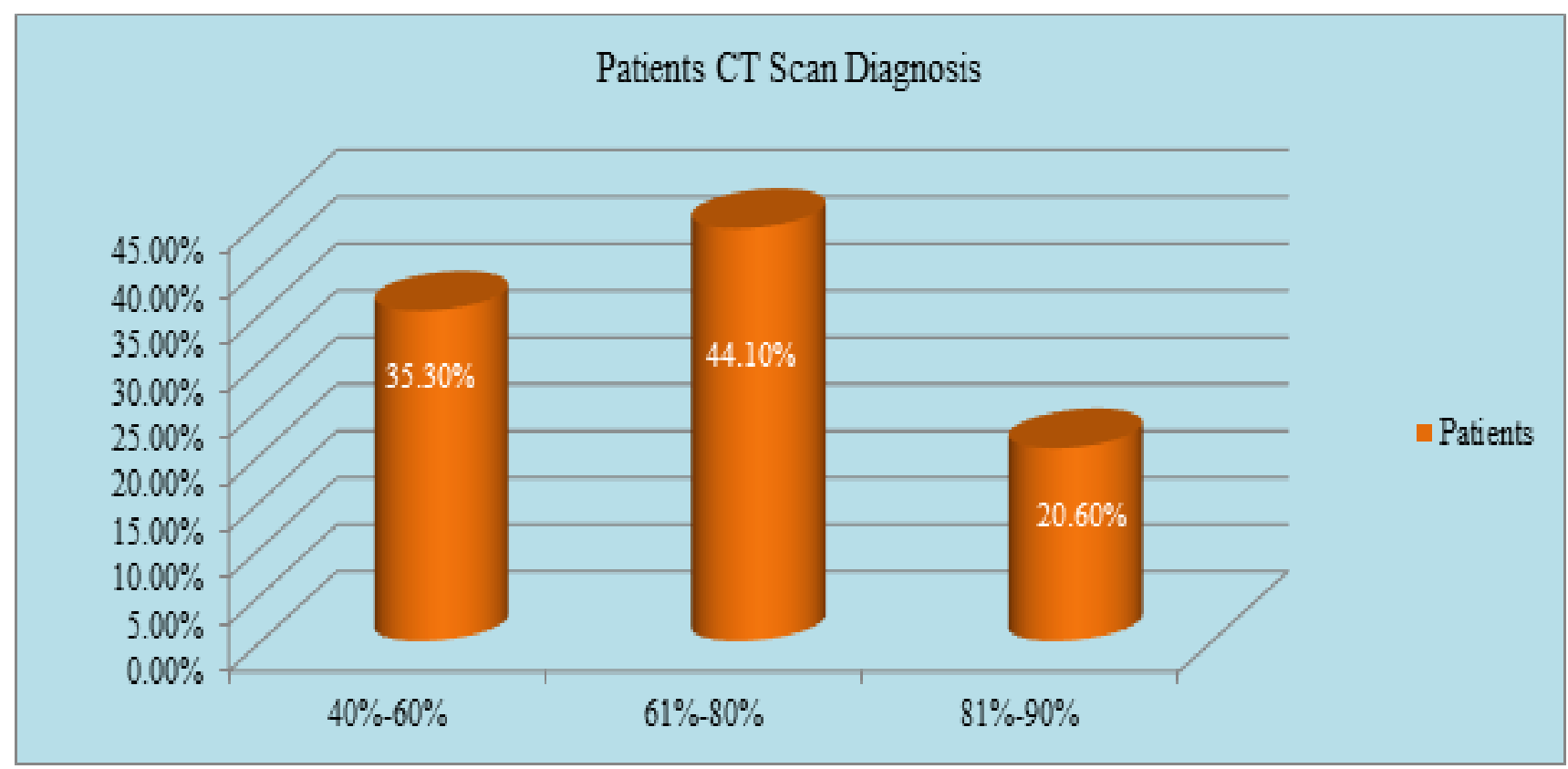

Figure 2: Diagnosed by CT scan of chest $(\mathrm{N}=34)$ 
Annals of International Medical and Dental Research

E-ISSN: 2395-2822 | P-ISSN: 2395-2814

Vol-8, Issue-2 | March-April 2022

DOI: 10.53339/aimdr.2022.8.2.18

Page no- 128-134 | Section- Research Article (Surgery)

Table 4: Condition of the patient during tube thoracostomy $(\mathrm{N}=34)$

\begin{tabular}{|l|c|c|}
\hline Condition of the patient during tube thoracostomy & $\mathbf{n}$ & $\mathbf{\%}$ \\
\hline On face mask with 10 lit/m O2 & 15 & $44.1 \%$ \\
\hline On non-rebreather mask with 16 lit/m O2 & 9 & $26.5 \%$ \\
\hline On high flow nasal cannula with 35-60 lit/m O2 & 6 & $17.6 \%$ \\
\hline On artificial ventilation & 4 & $11.8 \%$ \\
\hline
\end{tabular}

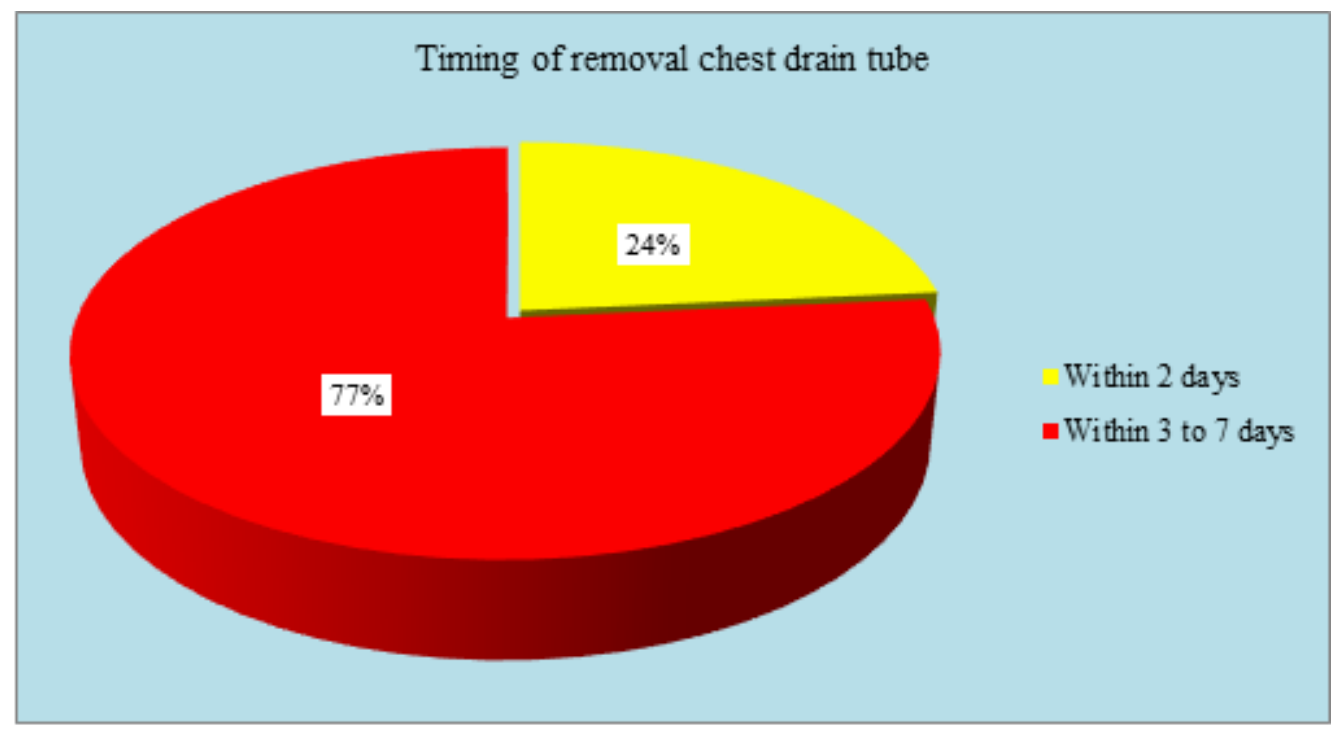

Figure 3: Timing of removal of Chest drain tube $(\mathrm{N}=34)$

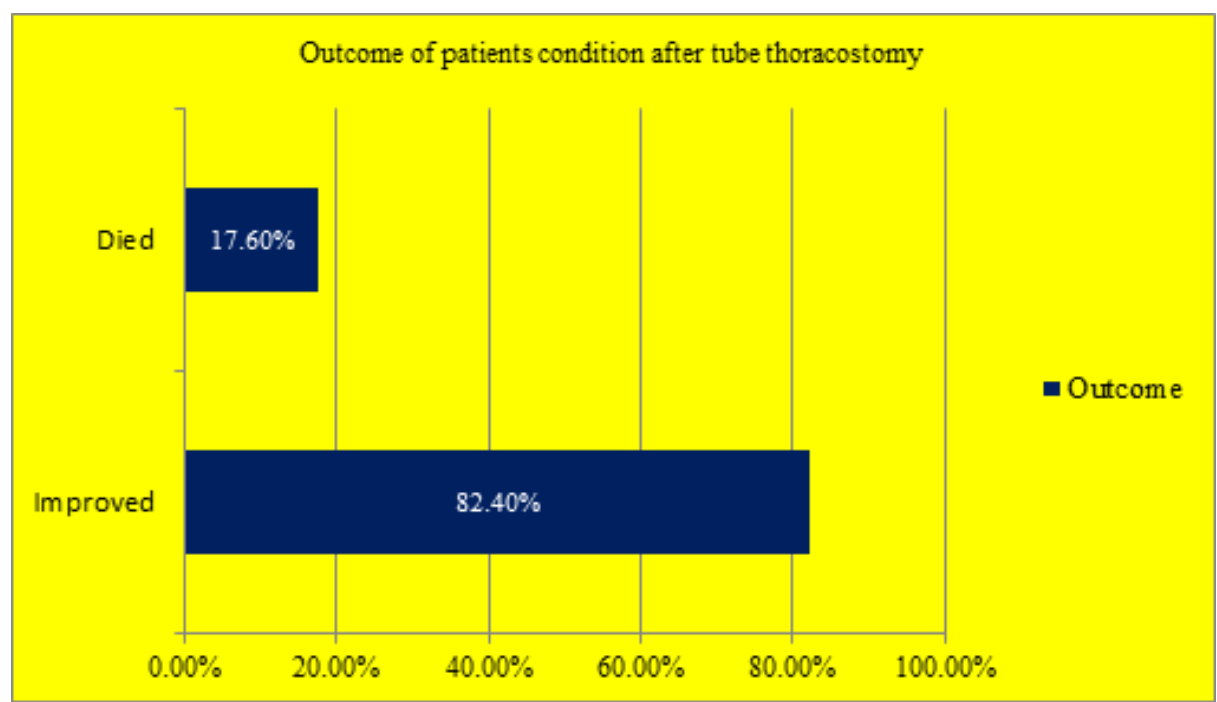

Figure 4: Outcome of Patient's condition after tube thoracostomy $(\mathrm{N}=34)$

[Figure 3] showed chest drain tube removal timing. It took 3 to 7days for highest no of the patients $(76.5 \%)$ for removing the tube while for $23.5 \%$ patients it took only 2 days. 
Annals of International Medical and Dental Research

E-ISSN: 2395-2822 | P-ISSN: 2395-2814

Vol-8, Issue-2 | March-April 2022

DOI: $10.53339 /$ aimdr.2022.8.2.18

Page no- 128-134 | Section- Research Article (Surgery)

There were no complications following the tube thoracostomy. Twenty-eight patients improved in relation to oxygen demand and left hospital in good health, and six patients died 3 days after tube thoracostomy who were in artificial ventilation and both had more than 81 percent lung involvement (fibrosis) diagnosed by CT scan of the chest [Figure 5]

\section{DISCUSSION}

The first instance of COVID-19 was discovered in China in December 2020. At all levels and in various specializations, the implementation of targeted medical initiatives has taken place since then. Throughout the course of the condition, we gained a better grasp of its various components. A cough and shortness of breath are the most common symptoms, but they aren't the only ones. Coughing and the resultant increase in intra-alveolar pressure are often cited by doctors as contributing factors in patients' thoracic problems. ME was more commonly detected in conjunction with SE or pneumothorax in SARS-CoV-1 cases than as a standalone entity.[] Observations in patients who were not intubated support the theory that alveolar damage is the result of disease rather than a side effect of mechanical ventilation. In fact, the presence of ME has been linked to a higher risk of intubation.[6] In addition, it was frequently a part of the culture. prelude to a greater risk of death Approximately $11.6 \%$ of SARS-CoV-1 patients developed ME. An air rim shadow on the outer edge of the heart usually indicates Naclerio's $\mathrm{V}$ sign [6]. In contrast to MERS and SARS CoV-1, COVID-19 displays a distinct disease pattern with ground-glass opacities that are more prevalent in the lower lobes.[7] We identified a strong link between these thoracic issues and patient outcomes, including the need for reintubation. Patients with pneumothorax treated with thoracostomy tube insertion had better outcomes in COVID19 patients who suffered thoracic problems in general. Patients who had indwelling thoracostomy tubes had a greater survival rate than those who received a more conservative treatment. As a general rule, conservative treatment is widely accepted in individuals with SE and ME without pneumothorax.[8] However, in our group of COVID-19 patients, we opted to implant a thoracostomy tube on the ipsilateral side of the SE. It was necessary to use a more active preventative approach due to the uniqueness of these individuals and the isolation limits in critical care and monitoring. In our research, there were no adverse effects from a tube thoracostomy. The condition of 28 patients improved in relation to their oxygen demand, and they were discharged from the hospital in good health; however, 8 patients who were on artificial ventilation and had CT scans of their chests that showed more than 81 percent lung involvement (fibrosis), died three days after their tubes were thoracostomized. In the "Safety triangle," the chest drain tube was always included. During the COVID-19 pandemic, the AAST Acute Care Surgery and Critical Care Committees provided instructions and recommendations for tube thoracostomy to all patients. Local anesthetic was used in each and every case (2 percent lignocaine injection). COVID-19 patients who were admitted to the ICU without developing thoracic difficulties and those who developed complications over their entire hospital stay showed a substantial difference in the severity of these complications and the impact they had on their patients. The disease process appears to play a significant influence in determining the extent of lung 
Annals of International Medical and Dental Research

E-ISSN: 2395-2822 | P-ISSN: 2395-2814

Vol-8, Issue-2 | March-April 2022

DOI: 10.53339/aimdr.2022.8.2.18

Page no- 128-134 | Section- Research Article (Surgery)

parenchyma loss and subsequent thoracic consequences. However, the author conducted a same study previously with small sample size during the first COVID-19 pandemic from July 2020 to August 202114 months period duration.[]

\section{CONCLUSIONS}

Acute care surgeons routinely perform tube thoracostomy for traumatic hemothorax or pneumothorax. There are no data on thoracostomy tube aerosolization of the severe acute respiratory syndrome coronavirus 2 , and the risk presumably varies depending on the indication. Special precautions to take during

\section{REFERENCES}

1. Pieracci FM, Burlew CC, Spain D, et al. Tube thoracostomy during the COVID-19 pandemic: guidance and recommendations from the AAST Acute Care Surgery and Critical Care Committees. Trauma Surg Acute Care Open. 2020;5(1):e000498. doi:10.1136/tsaco-2020-000498

2. Platnick C, Witt CE, Pieracci FM, Robinson CK, Lawless R, Burlew CC, Moore EE, Cohen M, Platnick $\mathrm{KB}$. Beyond the tube: Can we reduce chest tube complications in trauma patients? Am J Surg. 2021;222(5):1023-1028.

doi: 10.1016/j.amjsurg.2021.04.008.

3. Etoch SW, Bar-Natan MF, Miller FB, Richardson JD. Tube thoracostomy. Factors related to complications. Arch Surg. 1995;130(5):521-5. doi: 10.1001/archsurg.1995.01430050071012.

4. Kouritas VK, Papagiannopoulos K, Lazaridis G, et al. Pneumomediastinum. J Thorac Dis. 2015;7(Suppl 1):S44-S49. doi:10.3978/j.issn.2072-1439.2015.01.11

5. Ucpinar BA, Sahin C, Yanc U. Spontaneous pneumothorax and subcutaneous emphysema in the COVID-19 pandemic to reduce staff exposure risk during tube insertion, drainage system maintenance and tube removal are discussed. This material is not meant to replace clinical judgment. A tube thoracostomy should be placed in a life-threatening scenario regardless of whether or not the particular equipment listed below is available. As the pandemic evolves, any or all of the data and suggestions may become obsolete. In COVID-19 disease, non-iatrogenic pneumothorax, subcutaneous and mediastinal emphysema are associated with worse prognosis and outcomes. Pneumothorax may have a better prognosis and outcome than surgical and mediastinal emphysema.

COVID-19 patient: Case report. J Infect Public Health. 2020;13(6):887-889. doi: 10.1016/j.jiph.2020.05.012.

6. Udupa S, Hameed T, Kovesi T. Pneumomediastinum and subcutaneous emphysema associated with pandemic (H1N1) influenza in three children. CMAJ. 2011;183(2):220-222. doi:10.1503/cmaj.100099

7. Wali A, Rizzo V, Bille A, Routledge T, Chambers AJ. Pneumomediastinum following intubation in COVID19 patients: a case series. Anaesthesia. 2020;75(8):10761081. doi: 10.1111/anae.15113.

8. Mohan V, Ahmed Tauseen R. Spontaneous pneumomediastinum in COVID-19. BMJ. 2020;13(5):236519.

9. Saha H. Experience of 17 Cases of Tube Thoracostomy of COVID-19 Positive Patients During COVID-19 Pandemic Under Thoracic Surgery Unit of Bangabandhu Sheikh Mujib Medical University (BSMMU), Dhaka, Bangladesh. Cardiol Cardiovasc Med. 2021;5:695-703.

Source of Support: Nil, Conflict of Interest: None declared 